Article

\title{
Inferring Species Diversity and Variability over Climatic Gradient with Spectral Diversity Metrics
}

\author{
Amrita N. Chaurasia ${ }^{1}$, Maulik G. Dave ${ }^{1}$, Reshma M. Parmar ${ }^{1}$, Bimal Bhattacharya ${ }^{2}$, \\ Prashanth R. Marpu ${ }^{3}$ (D), Aditya Singh 4 (D) and N. S. R. Krishnayya ${ }^{1, *}$ \\ 1 Ecology Laboratory, Department of Botany, The Maharaja Sayajirao University of Baroda, Vadodara 390002, \\ Gujarat, India; amrita.n.c-botanyphd@msubaroda.ac.in (A.N.C.); \\ maulikdave-botanyphd@msubaroda.ac.in (M.G.D.); reshma.p-botanyphd@msubaroda.ac.in (R.M.P.) \\ 2 Space Applications Centre, Indian Space Research Organisation, Ahmedabad 380015, Gujarat, India; \\ bkbhattacharya@sac.isro.gov.in \\ 3 Department of Electrical Engineering and Computer Science, Khalifa University of Science and Technology, \\ Abu Dhabi 127788, UAE; prashanth.marpu@ku.ac.ae \\ 4 Department of Agricultural and Biological Engineering, University of Florida, P.O. Box 110570, Gainesville, \\ FL 32611-0570, USA; aditya01@ufl.edu \\ * Correspondence: nsr.krishnayya-botany@msubaroda.ac.in
}

Received: 24 May 2020; Accepted: 25 June 2020; Published: 2 July 2020

check for updates

\begin{abstract}
Filling in the void between forest ecology and remote sensing through monitoring biodiversity variables is of great interest. In this study, we utilized imaging spectroscopy data from the ISRO-NASA Airborne Visible InfraRed Imaging Spectrometer-Next Generation (AVIRIS-NG) India campaign to investigate how the measurements of biodiversity attributes of forests over wide areas can be augmented by synchronous field- and spectral-metrics. Three sites, Shoolpaneshwar Wildlife Sanctuary (SWS), Vansda National Park (VNP), and Mudumalai Tiger Reserve (MTR), spread over a climatic gradient (rainfall and temperature), were selected for this study. Abundant species maps of three sites were produced using a support vector machine (SVM) classifier with a 76-80\% overall accuracy. These maps are a valuable input for forest resource management. Convex hull volume (CHV) is computed from the first three principal components of AVIRIS-NG spectra and used as a spectral diversity metric. It was observed that $\mathrm{CHV}$ increased with species numbers showing a positive correlation between species and spectral diversity. Additionally, it was observed that the abundant species show higher spectral diversity over species with lesser spread, provisionally revealing their functional diversity. This could be one of the many reasons for their expansive reach through adaptation to local conditions. Higher rainfall at MTR was shown to have a positive impact on species and spectral diversity as compared to SWS and VNP. Redundancy analysis explained $13-24 \%$ of the variance in abundant species distribution because of climatic gradient. Trends in spectral CHVs observed across the three sites of this study indicate that species assemblages may have strong local controls, and the patterns of co-occurrence are largely aligned along climatic gradient. Observed changes in species distribution and diversity metrics over climatic gradient can help in assessing these forests' responses to the projected dynamics of rainfall and temperature in the future.
\end{abstract}

Keywords: species diversity; spectral diversity; convex hull volume; AVIRIS-NG; tropical forests; ISRO-NASA campaign; climatic gradient

\section{Introduction}

Forest communities across the globe are constantly affected by a combination of biotic and abiotic factors that impact their composition, structure, and function [1]. Understanding how regional and global environmental forcing act as drivers towards impacting species abundances [2], and how 
different facets of biodiversity affect ecosystem functioning at different scales [3], are critical aspects of research. Owing to a longer lifespan, trees have the ability to adapt to spatio-temporal variations in environmental conditions [4], and also play a vital role in determining ecosystem structure and function by large contributions to biomass [5]. These are more important for tropical forests with larger diversity, and the understanding of mechanisms determining ecosystem structure and distributions is significantly lacking [6,7].

Field-based biodiversity estimates are generally used to measure species richness and abundance [8]. Trait variability within a species may not be reliably measured with field-based studies [9] as it requires collecting large samples of data over wider regions. Linking field and remote sensing-based metrics can help in getting better estimates of trait variability and species distribution, and ecological and remote sensing communities are making efforts to blend these disparate areas of research towards more effective biodiversity assessment [10]. It is reported that intra- and inter-specific variations in plant functional traits are normally reflective of environmental variation across the species' ranges of occurrence, and are indirectly observable as emergent patterns of spatial variations in trait characteristics [11]. Wide area mapping with remote sensing [12] provides a divergent approach over field methods of sampling to monitor biodiversity. Hill et al. [13] highlighted the possible application of hyperspectral remote sensing towards monitoring forest functional diversity by comparing spectral variability. Proximal and airborne hyperspectral sensors, such as the Airborne Visible InfraRed Imaging Spectrometer (AVIRIS and AVIRIS-Next Generation (AVIRIS-NG)) have shown immense promise and potential in exploring inter- and intra-species variability and divergence in trait characteristics [14-16]. However, there are limited empirical investigations, thereby restricting our ability to find general mechanisms that link traits and competition in the main functional realms of the plant world [17].

It has been observed that measures of variation in the spectral characteristics of a remotely sensed image are related to species richness $[18,19]$. The observed spectral heterogeneity can act as a proxy of species diversity and has been linked to variability in plant community assemblages [20] and environmental gradients [21]. As an example, Dahlin [22] has demonstrated that the convex hull volume (CHV) computed from the first three principal components of AVIRIS-NG spectral data can be used to reveal key insights on the relative importance of drivers of community assembly, even in the absence of additional data about plant functional traits. So, CHV not only reduces the dimensionality of spectral data through principal component analysis (PCA), but can also be used as a spectral diversity metric [23]. Wang and Gamon [10] observed that spectral diversity metrics can provide cues about the "dimensionality" of spectral data of a target area, and future work on these lines can bring clarity about regulations linked to the "plant phylogenetic-functional-spectral relationship" that may enhance understanding about the remote sensing of biodiversity. A myriad of factors impact plant growth, response, and performance, and reports indicate that variability in environmental settings, such as grazing, climate change [24], climatic gradient [25], and precipitation gradient [26], impact plant functional trait responses. The present study is an attempt to check how well spectral diversity, measured as $\mathrm{CHV}$, can infer tropical tree species response to climate variability, such as different rainfall patterns and atmospheric temperature differences.

Some earlier studies presented a correlation between spectral diversity observed through remote sensing to species diversity and species response to climatic change in Amazonian forests [27] and North American biomes [28]. However, such studies are limited in the tropics and more so in regions with high heterogeneity and immense anthropogenic pressure. The tropics support most of the global diversity, and climate change has a significant impact on these diverse systems [1]. Climate impacted changes in the tree functional compositions of forests magnify the feedback of forest biomass [3]. Linking trait data to climate inputs can help in understanding how biodiversity and the associated functioning of the species are affected by climate change [29]. Other reports [30-32] show that tropical forests are directly affected by rainfall patterns. The forest ecosystems of India are not well studied using remote sensing data in spite of being diverse and vast [33], with a large number of areas listed as UN biodiversity hotspots [33]. Some earlier studies around the Godavari basin [34] and the 
Eastern Ghats [35] reported that multispectral data can be utilized in mapping forest cover features. Gairola et al. [36] presented a review of methodologies for ecological studies and suggested that high resolution remote sensing data are better suited to study the Indian Himalayan region due to the high diversity and heterogeneity of the landscape. Wieczynski et al. [29] advocated for the inclusion of trait and abundance data of the forest cover of underrepresented regions of the world to have a better understanding of the effect of climate change on the overall aboveground biomass content. To address this ecologically important aspect, the abundant species mapping of forest cover using remote sensing becomes an important target to achieve. The tropical forests of India are exposed to highly variable rainfall dynamics and the corresponding changes in their structure, function, and distribution have not been fully studied. This study aims at filling some of the gaps in our understanding about Indian forests and the changes happening in the diversity and distribution of tree species in the context of climate variability.

Trees with bigger canopy sizes can be easily distinguished with the spatial resolution of airborne remote sensing sensors [10]. AVIRIS-NG data, over some of the forest cover of India, were used to map dominant species and diversity metrics at a community level [37]. This study builds on earlier work and explores the possibility of linking field observations and diversity metrics derived from remote sensing data to assess the variability due to rainfall and temperature (henceforth referred to as climatic gradient). To this end, we investigate the following questions:

- How species diversity correlates with spectral diversity calculated from remote sensing;

- Can measured CHVs assist in elucidating the intra- and inter-species variability of abundant species;

- To what extent climatic gradient impacts the distribution of species and the associated spectral diversity.

\section{Materials and Methods}

\subsection{Site Description}

Three forest sites in India, Shoolpaneshwar Wildlife Sanctuary (SWS), Vansda National Park (VNP) in Gujarat, and Mudumalai Tiger Reserve (MTR) in Tamil Nadu, were selected for this study (Figure 1). The three sites are designated as protected areas and experience highly variable rainfall patterns, along with increasing anthropogenic pressure (Table 1). Mean annual rainfall is different in the three zones, with the lowest record at SWS and the highest at MTR. A temperature gradient is also observed, with MTR recording the lowest mean values and the highest being at SWS, which is an opposite trend to that of rainfall (Table S1). Such variation in climate is expected to affect the species distribution, diversity, and abundance, which is of interest in this work. Different steps carried out in the study are schematically represented in Figure 2.

Table 1. Physiographic characters and decadal means of rainfall and temperature data of the three sites.

\begin{tabular}{|c|c|c|c|c|c|c|}
\hline \multirow{2}{*}{ Sites } & \multicolumn{2}{|c|}{ Location } & \multirow{2}{*}{$\begin{array}{l}\text { Area } \\
\left(\mathbf{k m}^{2}\right)\end{array}$} & \multirow{2}{*}{$\begin{array}{c}\text { Average } \\
\text { Elevation }(\mathrm{m})\end{array}$} & \multirow{2}{*}{$\begin{array}{c}\text { Rainfall } \\
(\mathrm{mm})\end{array}$} & \multirow{2}{*}{$\begin{array}{c}\text { Temperature } \\
\left({ }^{\circ} \mathrm{C}\right)\end{array}$} \\
\hline & Lat $\left({ }^{\circ} \mathbf{N}\right)$ & Lon $\left({ }^{\circ} \mathrm{E}\right)$ & & & & \\
\hline SWS & 21.88 & 73.65 & 607.70 & 287 & 1210.66 & 27.00 \\
\hline VNP & 20.82 & 73.44 & 23.99 & 169 & 1557.72 & 26.52 \\
\hline MTR & 11.73 & 76.46 & 688.00 & 1233 & 1731.88 & 24.84 \\
\hline
\end{tabular}




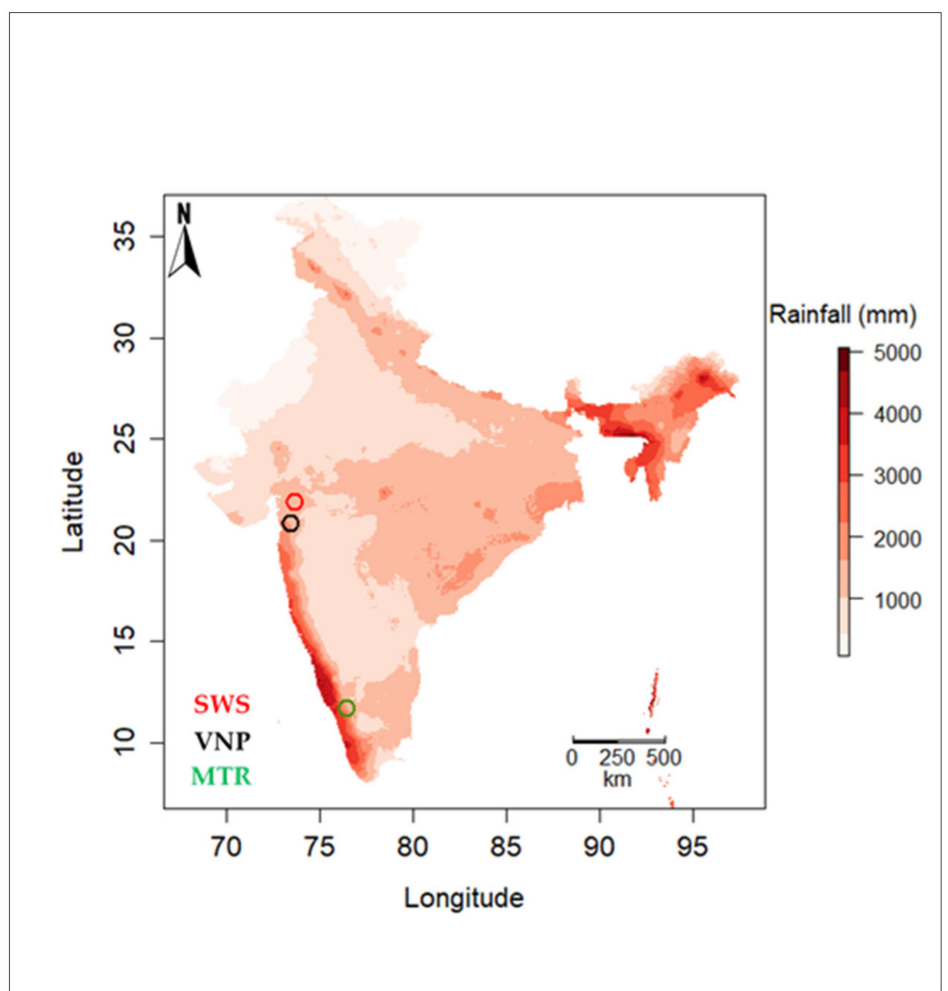

Figure 1. Map showing the location of the three study sites, Shoolpaneshwar Wildlife Sanctuary (SWS), Vansda National Park (VNP), and Mudumalai Tiger Reserve (MTR). The color gradient indicates decadal mean rainfall across the country.

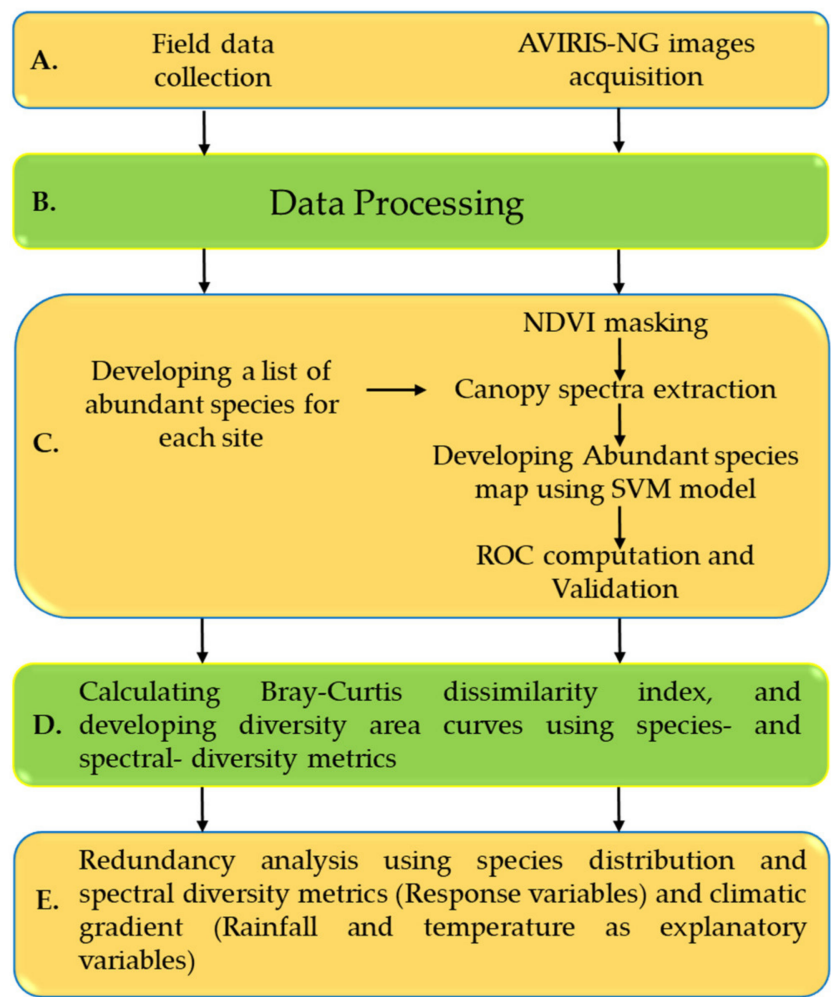

Figure 2. Schematic view of the workflow carried out. 


\subsection{Vegetation Characteristics}

The forests of all three sites support tree species with diverse physiognomies and phenological characteristics. The tree species of SWS and VNP are largely deciduous with a few evergreens. MTR also supports both deciduous and evergreens, with a larger proportion of evergreen species $(\sim 25 \%)$. Plantations of teak and bamboo at SWS and VNP, and teak, bamboo, eucalyptus, and silver oak at MTR constitute sizable proportions of tree cover. Amongst the tree species recorded during field study at each site, some of the species showed widespread distribution (referred as abundant species), while others are sparse (referred to as lesser distributed species). Table S2 illustrates common tree species found in the three sites.

\subsection{Field Data Collection}

Initial field surveys were conducted \pm 5 days from the image acquisition dates (Table 2) for each site. Field work includes the marking and registering of field plots, recording the phenological phases of tree species, and the collection of foliar samples from representative individuals of each species observed in these plots. Sites were revisited in subsequent months to perform detailed species inventories. Registered field plots and additional ones were laid across the length and width of the flight path at the three sites over accessible terrain (Figure 3). During the initial field visits, it was noticed that individual trees of some of the commonly occurring species were spread over $>4 \mathrm{~m}$, and the expected spatial resolution from the flight campaign was 4-8 $\mathrm{m}$. Keeping in view of the observed distribution of tree species in the field, and the suggestive spatial resolution of the sensor, quadrats of 8 $\mathrm{m} \times 8 \mathrm{~m}$ were randomly laid down across trails of forest cover, some away from the trail (nearly 200 at each site). In addition to these, three to five polygons of varying sizes $\left(500-750 \mathrm{~m}^{2}\right)$ were laid out. The number of quadrats at each site, and the size of the polygons considered, was primarily based on the observed vegetation characteristics and remarks of the local forest officials. All trees of more than 4 $\mathrm{cm}$ in diameter at breast height (dbh), falling within each quadrat and polygon, were counted. Tree species diversity, stem density, height, and canopy spread were measured and trees were identified to the species level with the help of field manuals, consultations with local residents, and forest service personnel. Tree crowns and field plots were geolocated using a handheld global positioning system (GPS) unit (Garmin Ltd. Olathe KS, USA) with $<3 \mathrm{~m}$ accuracy. The GPS readings were noted after three minutes of position averaging for better accuracy. Qualitative observations showed that the progression and duration of the senescent phase differed amongst species and across the three sites. The proportion of leaves fallen from the canopy also differed between species and the three sites. Few species were fully foliated with greener crowns.

Table 2. Summary of Airborne Visible InfraRed Imaging Spectrometer-Next Generation (AVIRIS-NG) image data.

\begin{tabular}{cccccc}
\hline Sites & $\begin{array}{c}\text { Flight } \\
\text { Elevation } \mathbf{( k m )}\end{array}$ & $\begin{array}{c}\text { Image } \\
\text { Acquisition } \\
\text { Date }\end{array}$ & $\begin{array}{c}\text { Image } \\
\text { Acquisition Time } \\
\text { (GMT +5:30) }\end{array}$ & $\begin{array}{c}\text { Flight } \\
\text { Footprint } \\
\text { Length (km) }\end{array}$ & Cloud Cover \\
\hline MTR & 4.83 & 05-Jan-2016 & $10: 62: 47-12: 81: 39$ & 42.22 & Clear to hazy \\
SWS & 4.15 & 08-Feb-2016 & $12: 58: 43-13: 61: 58$ & 44.85 & Clear \\
VNP & 4.16 & 09-Feb-2016 & $11: 02: 17-11: 57: 46$ & 13.32 & Clear \\
\hline
\end{tabular}




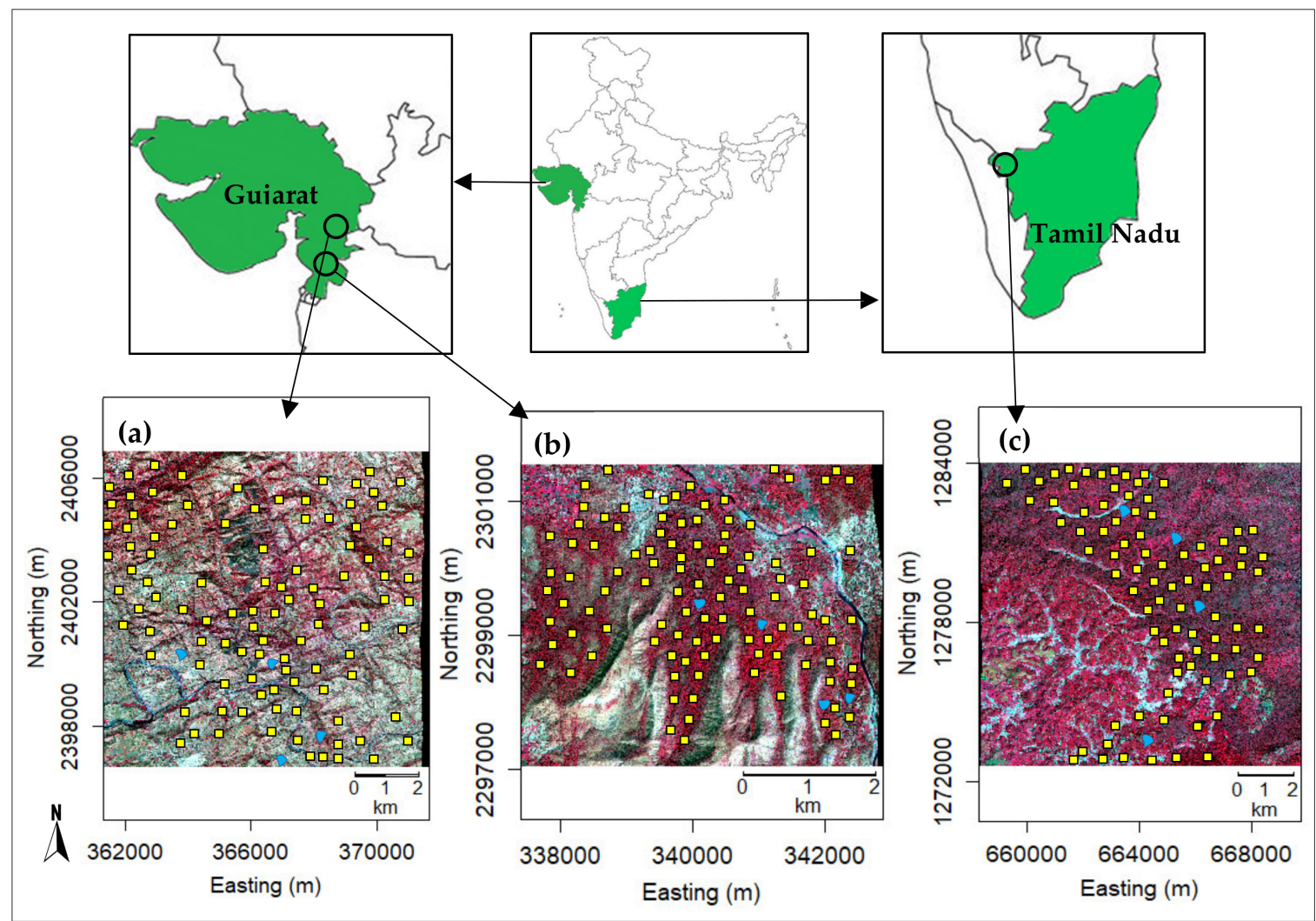

Figure 3. Sampled quadrats (yellow) and polygons (blue) established during field study. (a) SWS, (b) VNP, and (c) MTR.

\subsection{Climatic Data}

Following Diaz et al. [25], variability in the measurements of temperature and rainfall together are referred to as climatic gradient. We assessed two different datasets for sourcing temperature and rainfall data on annual, decadal, and long-term timescales from European ReAnalysis-Interim (ERA-Interim) and Climate Hazards Infrared Precipitation with Station data (CHIRPS). Data were projected to a spatial resolution of $5.12 \mathrm{~km}\left(0.05^{\circ}\right)$ for CHIRPS data and $12.5 \mathrm{~km}\left(0.125^{\circ}\right)$ for ERA-Interim data and extracted for all sampling locations at the three sites. The meteorological data from 1984-2016 indicated a spatial rainfall gradient from MTR (wetter) to VNP to SWS (lesser wetter, more arid). Annual, decadal, and long-term mean minimum and maximum temperatures had with minor variations at the three sites. Decadal mean rainfall and temperature at MTR are $\sim 40 \%$ higher and $\sim 4 \%$ lower compared to SWS (Table S1).

\subsection{AVIRIS-NG Data Acquisition and Processing}

As part of a joint campaign between the Indian Space Research Organization (ISRO) and the National Aeronautics and Space Administration (NASA, USA), the AVIRIS-NG sensor was flown over a large number of sites in India between October 2015 and February 2016. AVIRIS-NG acquired data at wavelengths from 380 to $2510 \mathrm{~nm}$ with $5 \mathrm{~nm}$ spectral sampling. The sensor was flown on a King Air B200 at a 4000-8000 m elevation, with resulting pixel sizes of 4-8 m, depending on flight altitude. The spatial resolution of the AVIRIS-NG data of the three sites considered in this study was $4 \mathrm{~m}$. The instrument measurements were calibrated and atmospherically corrected following Thompson et al. [38]. Airborne imaging spectroscopy data were subject to significant sun-sensor surface illumination effects due to both topography and anisotropic reflectance by vegetation. These were corrected following methods in Soenen et al. [39] and Wanner et al. [40] (code available at https://github.com/EnSpec/HyTools-sandbox) resulting in topographically and bidirectional reflectance 
distribution function (BRDF)-corrected images. Details of the AVIRIS-NG image data acquisition are given in Table 2.

The topographically and BRDF-corrected data were mosaicked into contiguous blocks for all sites. Noisy bands $(<411 \mathrm{~nm})$ and water absorptions bands $(1348-1428,1778-1949 \mathrm{~nm})$ were removed, resulting in final image spectral subsets comprising a total of 366 usable bands (from a total of 425). The normalized difference vegetation index (NDVI) of each image was used primarily to generate non-forest masks with thresholds of 0.4 (SWS and VNP) and 0.6 (MTR) based on visual observations. The difference in NDVI threshold values is because of the observed variability in canopy greenness and senescent phases at the time of the flight pass over the three sites. To lower the overall brightness variation, a continuum removal (CR) transformation was also applied (as in [22]). These CR-transformed data were considered for further processing.

$$
N D V I=\frac{\rho_{860}-\rho_{650}}{\rho_{860}+\rho_{650}}
$$

\subsection{Data Analysis}

\subsubsection{Field Data Analysis}

The data of the quadrats laid down in field plots were pooled (10 quadrats in each field plot), resulting in 20 field plots for SWS, 19 for VNP, and 21 for MTR. Abundance data of each site at the laid down quadrats and polygons indicated that 20 species are abundant at each site, covering $75-80 \%$ of the forest of each site (henceforth referred to as abundant species). Species with lesser occupancy of each site are together referred to as lesser distributed species. The BiodiversityR package [41] has been used for analyses of field data. Kindt's exact method [41] was used for plotting tree species area accumulation curves using 1000 permutations for each site. These curves were developed for all the recorded species and the abundant species of each site. We tested different methods to obtain estimates of the number of tree species for each site (first- and second-order Jackknife, Chao, and Bootstrap), with an expectation that the tree species richness estimates of a site would be better characterized by using a range than a single one. Bray-Curtis dissimilarity graphs were developed to assess the dissimilarity in the composition of any pair of field plots of a site. Estimated values for the Bray-Curtis dissimilarity distance ranged between 0 and 1 depending on the $100 \%$ similarity (0) or complete dissimilarity (1) of existing species in a pair of plots. Akin to species-area curves, Bray-Curtis graphs were developed for all the recorded species and abundant species.

\subsubsection{Abundant Species Mapping with the Support Vector Machine (SVM) Model}

A spectral library of crown-level reflectance spectra for the abundant tree species of each site (20 species at SWS and VNP, 19 in MTR) was developed for all the three sites using field records. At many points, we could obtain abundant species having a canopy spread of $>5 \mathrm{~m}$ or as pure patches with $>15 \mathrm{~m}$ spread (Table 3). These locations were utilized to extract the canopy spectra of each abundant species. Data from the canopy spectral library were used to develop species maps of each site. The classification of the images to map the abundant species required an abundant species map of each site to assess differences, if any, in these tree species distributions, and spectral diversity as CHVs, across the climatic gradient. Minimum noise fraction (MNF) transformation [42] was applied to the CR-transformed spectral dataset for feature reduction. A supervised classification of the abundant species of each site was performed using the support vector machine (SVM) method [43] using the MNF-transformed canopy spectra of each species. The parameters of the SVM model are optimized using three-fold cross-validation based on the available training data. After visual screening, the first 16 bands (for SWS and MTR) and the first 17 bands (for VNP) of MNF were selected as inputs for the SVM model to develop an abundant species map of the three sites. The field data were separated as training and testing data with a 60:40 ratio. For the SWS and VNP sites, additional field visits were 
carried out to validate randomly selected locations from the species map for an additional level of verification of classification accuracy.

Table 3. Measured biophysical parameters of the tree species at each site.

\begin{tabular}{ccccccc}
\hline \multirow{2}{*}{ Sites } & \multicolumn{3}{c}{ Height $(\mathbf{m})$} & \multicolumn{3}{c}{ Canopy Area $\left(\mathbf{m}^{\mathbf{2}}\right)$} \\
\cline { 2 - 7 } & Mean $( \pm \mathbf{S D})$ & Min & Max & Mean $( \pm$ SD) & Min & Max \\
\hline SWS & $12.48 \pm 4.80$ & 2.60 & 25.80 & $55.91 \pm 65.27$ & 2.41 & 613.80 \\
VNP & $18.31 \pm 6.30$ & 3.50 & 35.00 & $71.89 \pm 70.44$ & 2.55 & 446.93 \\
MTR & $22.90 \pm 7.56$ & 6.00 & 39.00 & $75.45 \pm 74.66$ & 2.41 & 638.20 \\
\hline
\end{tabular}

\subsubsection{Spectral Diversity Area Curves and Metrics}

Spectral diversity metrics were generated both from NDVI masked standalone images and from the abundant species maps of each site. Three different ways were followed to assess the applicability of spectral diversity metrics towards gauging tree species diversity. In the first approach, to understand the applicability of hyperspectral data in measuring diversity sans field study inputs, 175 squares $(10 \times 10$ pixels) per site were randomly extracted from an NDVI masked image of each site. The CR-transformed spectral data of the extracted squares of each site were analyzed based on Dahlin [22]. Principal component analysis (PCA) was performed to reduce the dimensionality of the data with the resulting components accounting for most of the total variance. The first three principal components accounted for $94 \%$ of the variation in the recorded spectral data. Two spectral diversity measures, the sum of variance of the first three PCs and the convex hull volume value, were calculated [22]. The CHV quantifies the volume of the trait space occupied by species in a community regardless of the shape of the distribution and represents the multivariate equivalent of range [44]. The sum of variance of the first three PCs and CHV values derived from spectral data of this study were empirically considered as proxies towards showcasing the tree species functional trait diversity of each site, as noted in Dahlin [22]. These data were also used to verify whether the spectral diversity metric was altered in lieu of the changes in species diversity expected across the forest cover of each site.

In the second approach, to find out the relation between the field-measured species diversity of the plots and the spectral diversity of the remote sensing measurements over the same, the spectral data of areas falling within Ground Control Points (GCPs) locations of the plots (20 of SWS, 19 of VNP, and 21 of MTR) of each site were extracted and CHV values from the CR-transformed spectral data of each plot were calculated and used to make a moving average-based spectral diversity area curve. This curve represented the spectral diversity of the species recorded during field study.

In the third approach, a number of plots of similar sizes, coinciding with the field study, were selected from the abundant species maps of each site, spectral data were extracted, and CHVs were calculated. The patterns identified in this approach were considered as abundant species spectral diversity-area curves, as the spectral data were based on the derived classification map indicating abundant species in the regions of interest. To analyze the one-to-one relationship between the number of abundant species and cumulative spectral diversity, equal numbers of canopy spectra $(n=10)$ of each abundant species were successively added and $\mathrm{CHVs}$ were calculated. A linear regression line was drawn between species numbers and CHVs. In another way, equal sized plots $(0.5 \mathrm{ha}, \mathrm{n}=5)$ were chosen from subsets of abundant species maps with a varied number of species. The CHVs of extracted spectral data were calculated to observe whether the value changed with species number.

\subsubsection{Intra- and Inter-Species Variability, CHV Values}

The abundant species maps derived from the remote sensing data were used to test the strength of spectral data as proxies for functional trait diversity in explaining the impact of climatic gradient on tree inter- and intra-species variability. Fifty spectra of each of the common abundant species (five tree species) of three sites were extracted from each of the CHIRPS $0.05^{\circ}$ grid cells based on the abundant 
species maps. The CHVs of the extracted spectral data of each of the common abundant species falling in CHIRPS grid cells at each site were calculated and plotted against CHIRPS decadal mean rainfall data. The expectation was that the CHV values of each of these five common tree species did not vary significantly without being impacted by the observed climatic gradient.

\subsubsection{Redundancy Analysis}

To look at the impact of climatic gradient on the tree species diversity, distribution, and spectral diversity of the three sites, redundancy analysis (RDA) was performed. RDA is a constrained ordination technique that directly relates the relative abundance of species across environmental gradients [41] and allows for establishing relationships between observed gradient of abundances vis-à-vis environmental drivers considered here as a climatic (rainfall-temperature) gradient. Analyses were performed using field plot data, the CHVs of plots for all recorded species, and abundant species (response variables) against recorded climatic gradient (explanatory variable).

\section{Results}

\subsection{Tree Species Diversity, Distribution}

A total of 123 tree species were recorded during field study at the three sites, of which 31 species were found to be common at all three sites. The recorded tree species richness was similar at VNP and SWS (68 and 70, respectively) but relatively higher at MTR (80 species). Amongst different the methods employed to estimate the species richness of each site, the Bootstrap method showed relatively closer values to the observed ones, as shown in Table S3. Estimates also showed a greater richness of species at MTR over the other two sites. A list of the common species at the three sites and the abundant species at each site are given in Tables S2 and S4. Species abundance data obtained from field plots was corroborated with observed distributions in larger polygons (Figure 2) laid down during field study, and were found to be matching. Log-based rank abundance curves of the abundant tree species, and all the recorded species of each site, showed variable width and similar slopes, indicating variability in the occurrence of these species (Figure S1). Lesser distributed species were in the lower part of the abundance curve, with many having the same rank. Site specificity was evident in the recorded tree species diversity, and the distribution of tree species, across the rainfall gradient. The most abundant and common tree species across three sites were Ficus racemosa, Tectona grandis, Terminalia bellirica, and Terminalia tomentosa. Bamboo (Dendrocalamus strictus at SWS and VNP and Bambusa bambos at MTR) was the fifth most common abundant species at the three sites. The relative distribution of common abundant species and their hierarchy, as seen in the abundant species maps, was not the same at the three sites (Figure 4). The distribution of T. grandis increased with an increase in rainfall, while bamboo species showed a reverse trend. T. bellirica showed lesser spread at VNP, while T. tomentosa showed higher spread, indicating intra-genus inconsistency in spread.

The phenology of deciduous and evergreen tree species showed diverse phases at the three sites at the time of the AVIRIS-NG flight pass. Differences within deciduous species were also noticed. Deciduous species at MTR appeared greener compared to the other two sites. The recorded biophysical parameters of trees, such as height and canopy spread, were higher at MTR compared to the other two sites. Marked trees with larger dimensions (Table 3), and the recorded clusters of some of the species during field study, made it possible to develop a canopy spectral library of abundant species. This effectively assisted in developing abundant species maps of each site with better accuracy. 


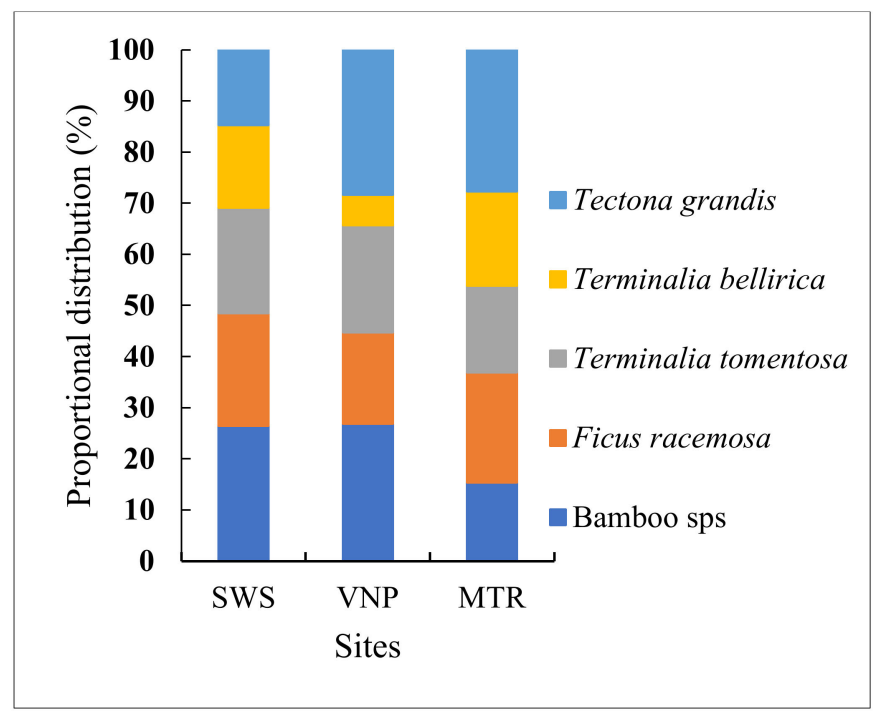

Figure 4. Proportional distribution of five common abundant species across the three sites from abundant species maps.

\subsection{Abundant Species Maps}

The support vector machine (SVM) classification model for the abundant species of each site performed well, with accuracies of $80.15 \%, 76.32 \%$, and $78.54 \%$ and kappa $0.79,0.75$, and 0.76 for SWS, VNP, and MTR, respectively, as shown in Tables S5-S8. Accuracy measures were cross-verified with receiver operating characteristic (ROC) curves for each species, and the area under the curve (AUC) was calculated (Figure S2 and Table S9). The mean AUC value for each site was 0.99, 0.98, and 0.94 for SWS, VNP, and MTR, respectively, showing the subtlety and specificity of the accuracies of the developed species maps. These maps were used to inquire about how spectral diversity metrics derived from remote sensing data can reveal species diversity and distribution. Figure 5 shows how the abundant species were spread at each site. The spread of common species was distinctive and site-specific. Spectral diversity, calculated as $\mathrm{CHV}$, increased with species number and their relationship showed high $R^{2}$ values (Figure 6), indicating that metrics of spectral data can be used/tested as a proxy for species diversity inputs for unexplored and relatively inaccessible forest cover. The CHVs of spectral data obtained from plots of 0.5 ha size selected from abundant species maps showing different species numbers increased with an increase in species numbers, as shown in Figure 6. Species specific to MTR, such as $C$. tetraandra and F. tsjahela, showed higher CHVs. Seed-propagated abundant species showed relatively higher $\mathrm{CHV}$ values compared to vegetation-propagated ones, as can be observed in Table S10. This supports the common understanding that diversity is usually greater in seed-propagated species compared to species showing vegetative propagation. 


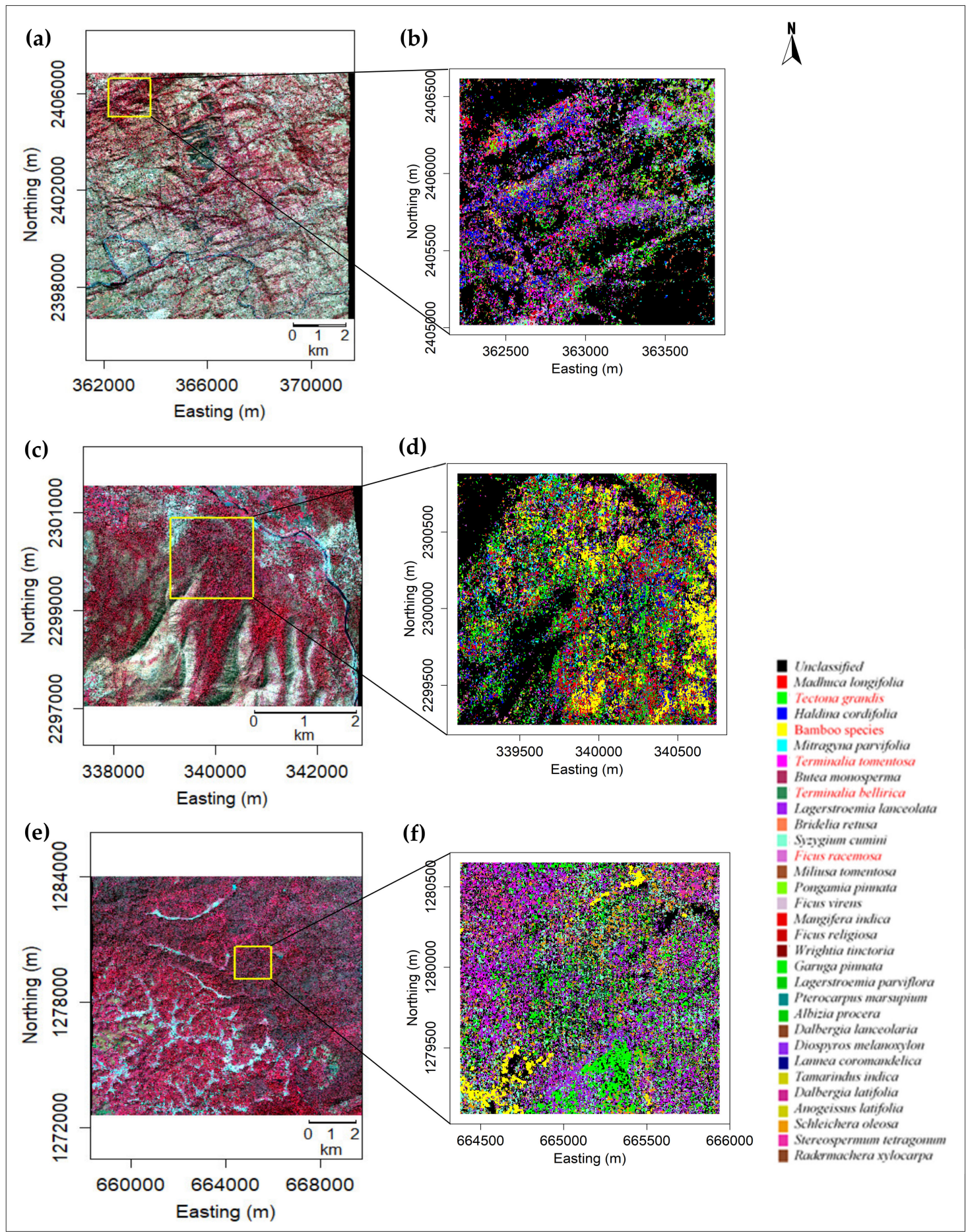

Figure 5. RGB image $(R=862 \mathrm{~nm}, \mathrm{G}=652 \mathrm{~nm}, \mathrm{~B}=552 \mathrm{~nm})$ and zoomed in subset of abundant species classification maps of the three sites (a,b: SWS, $\mathbf{c}, \mathbf{d}:$ VNP, $\mathbf{e}, \mathbf{f}:$ MTR). The abundant species color code is the same as for Figures 4 and 5 . The names of common abundant species at the three sites are marked in red-colored font. 


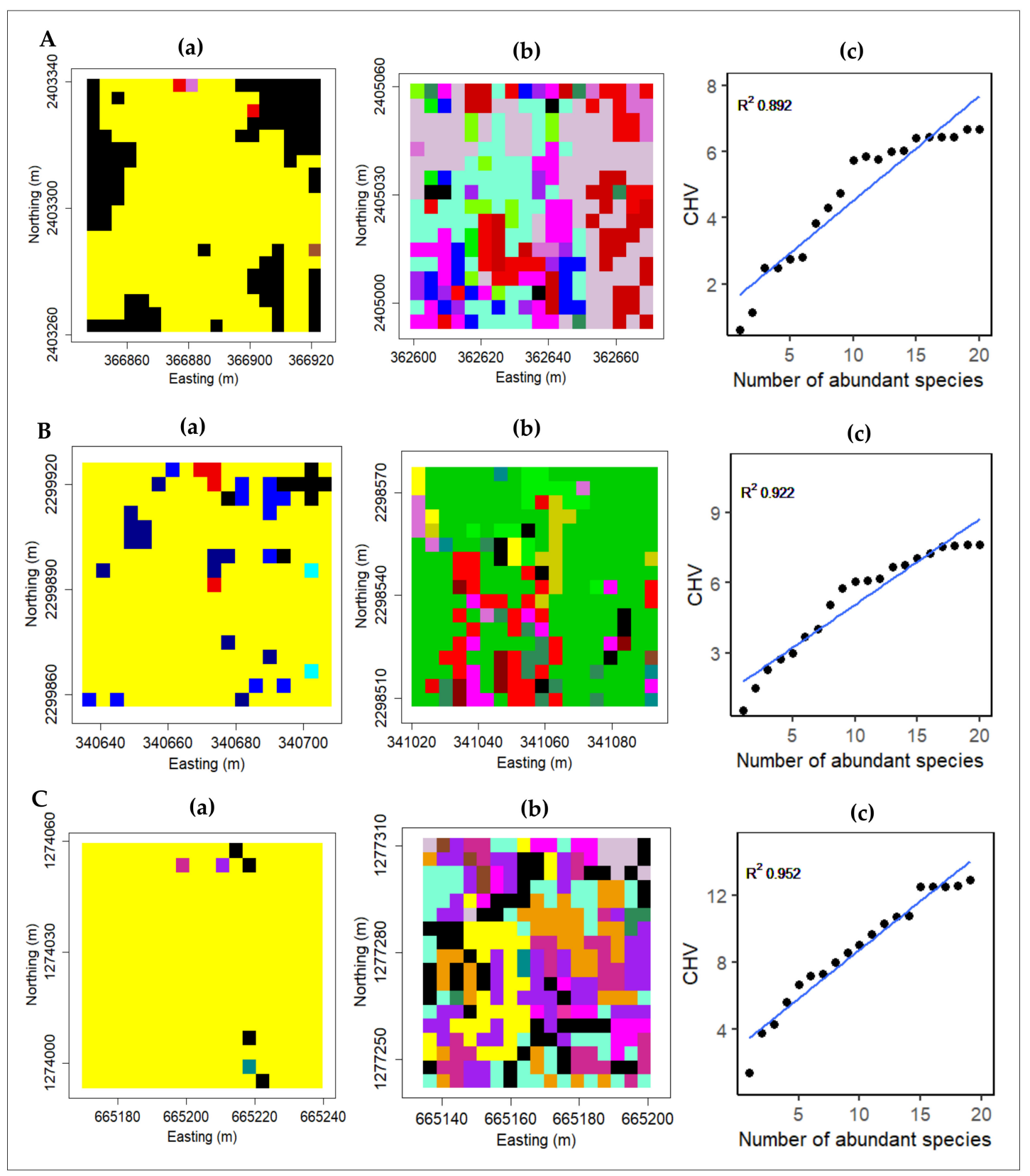

Figure 6. Convex Hull Volumes CHVs of 0.5 ha plots $(n=5)$ selected from abundant species maps of the three sites (A: SWS, B: VNP, C: MTR) with different numbers of occupant species; CHV values are: $a=2.41(n=4), b=6.05(n=12)$ for SWS, $a=3.31(n=5), b=5.65(n=12)$ for VNP, and $a=1.86$ $(\mathrm{n}=4), \mathrm{b}=6.1(\mathrm{n}=11)$ for MTR; Regression lines are of cumulative CHVs and the number of abundant species. (a) represents 0.5 ha plot with lower diversity $(n=4$ or 5$)$; (b) represents 0.5 ha plot with higher diversity ( $\mathrm{n}=11$ or 12$)$; (c) Regression lines of cumulative CHVs.

\subsection{Diversity-Area Curves}

Species diversity-area curves revealed a higher diversity at MTR compared to SWS (Figure 7). Spectral diversity-area curves developed for the three sites by following three different approaches showed distinguishing patterns. Firstly, to test the approach given in Dahlin [22] for these lesser studied sites, the sum of variance of the first three PCs and CHV were used to compare spectral diversity within and across the three sites. This approach revealed the utility of remote sensing data in measuring biodiversity variables sans field inputs. The results of this approach account for the spectral diversity of standalone tree cover diversity in the forests of each site. Spectral diversity-area 
curves of the summed variance of 175 plots showed an increase in variance over the observed climatic gradient, with the lowest value at SWS and the highest at MTR (Figure 7). The CHVs of 175 plots at MTR were nearly twice the value of SWS (Table S11), indicating greater spectral diversity over the climatic gradient. Spectral diversity-area curves from the other two approaches also showed that spectral diversity increased over the observed climatic gradient. Abundant species at each site showed higher spectral diversity compared to the recorded tree species (Figure 7).

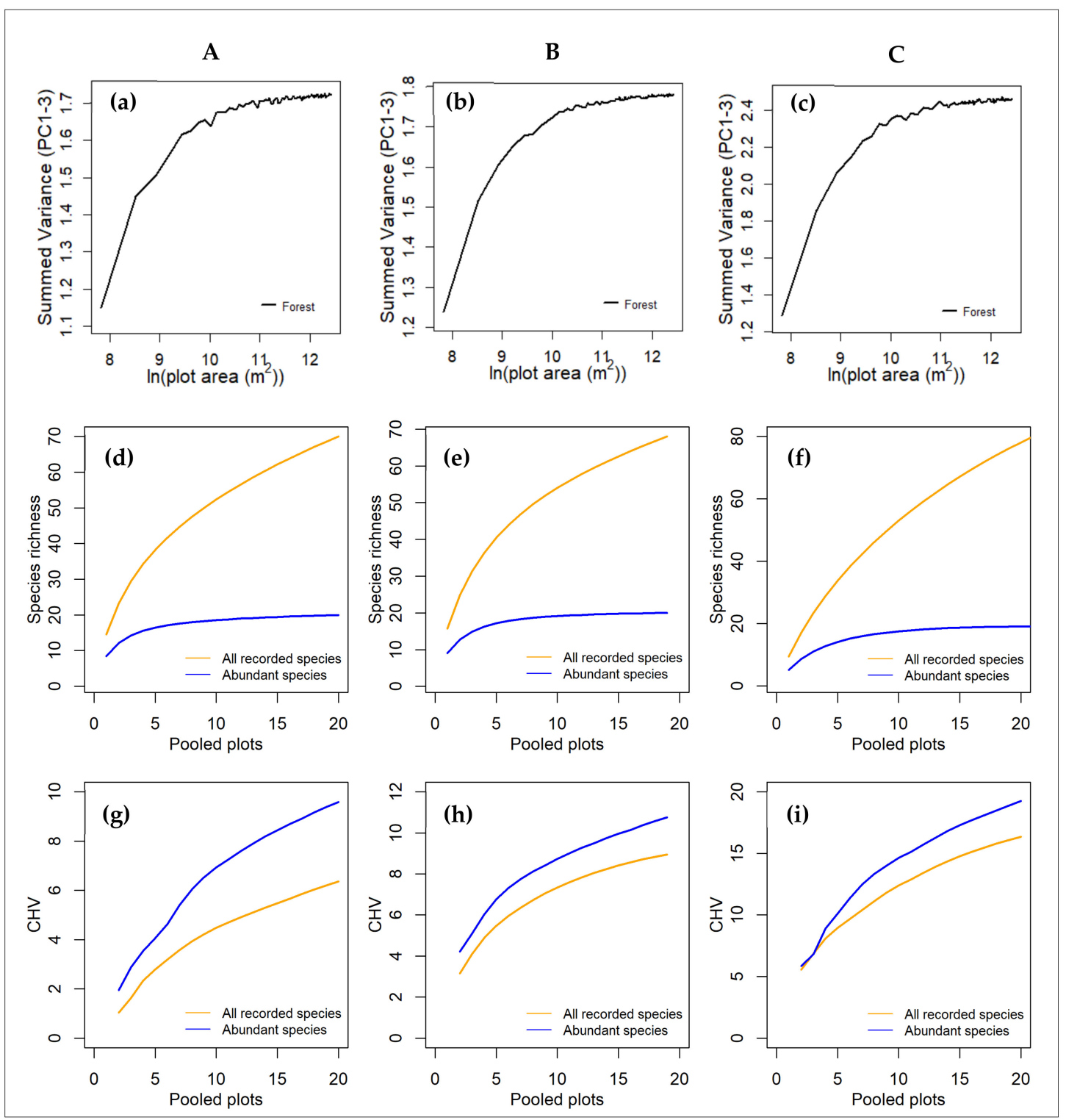

Figure 7. Diversity area curves (A: SWS, B: VNP, C: MTR). Spectral diversity-area curves for the summed variance of 175 plots $(\mathbf{a}-\mathbf{c})$; Species diversity-area curves $(\mathbf{d}-\mathbf{f})$; Cumulative CHVs and area curves $(\mathbf{g}-\mathbf{i})$.

Heat maps of Bray-Curtis dissimilarity graphs between plots developed for all the recorded species and abundant species showed differences in the values of species and spectral diversity (as $\mathrm{CHVs}$ ) metrics. For the SWS and VNP sites, values measured from the spectral diversity metrics were higher compared to the ones coming from field metrics. At MTR, the values were the same for both field and spectral data metrics (Figure 8 and Figure S3). 


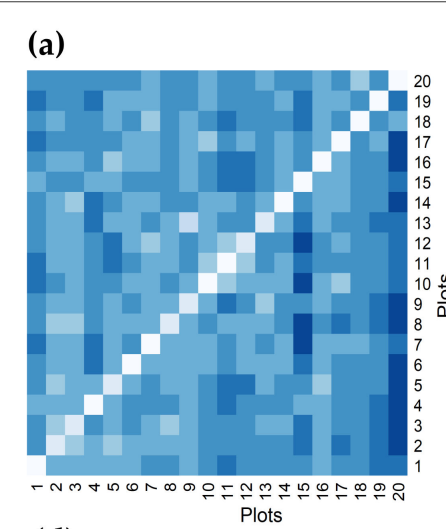

(d)

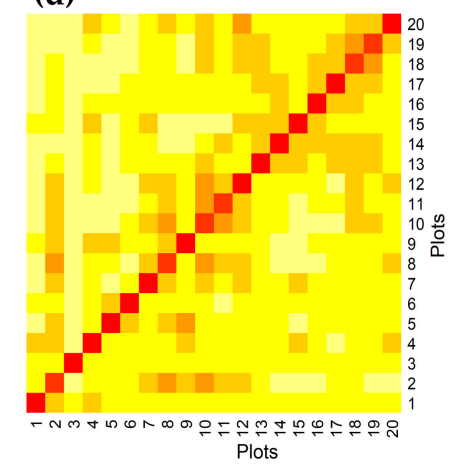

(b)

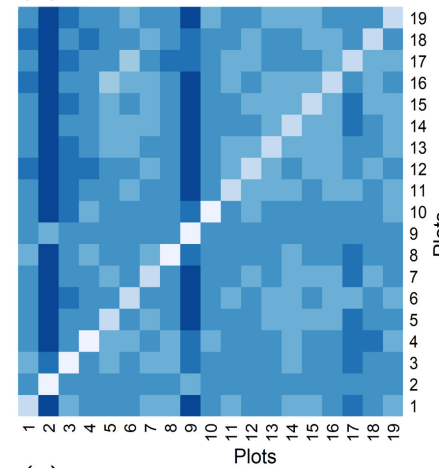

(e)

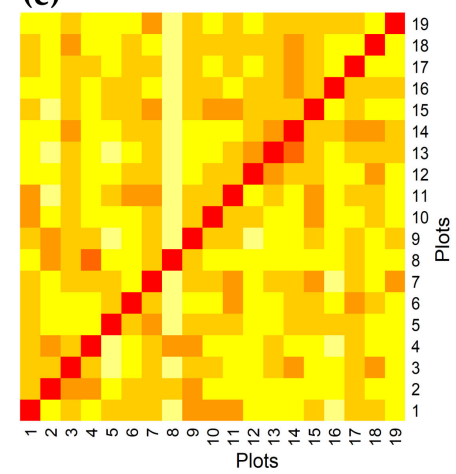

(c)

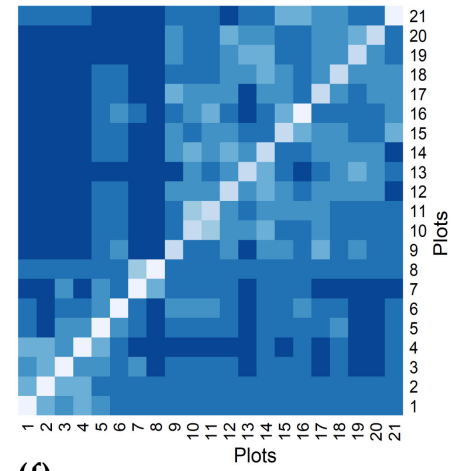

(f)

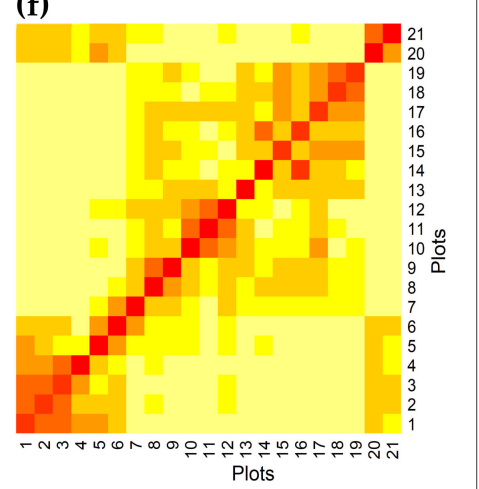

Figure 8. Heatmap of Bray-Curtis dissimilarity graphs of abundant species. The mean dissimilarity value of species abundance (blue) and that of spectral diversity as CHVs (yellow) are (a) 0.64 and (d) 0.81 for SWS, (b) 0.56 and (e) 0.68 for VNP, and (c) 0.81 and (f) 0.81 for MTR.

\subsection{Intra- and Inter-Species Spectral Diversity, Rainfall Gradient}

The abundant species maps developed from AVIRIS-NG datasets were found to be very useful in finding the intra- and inter-spectral variability of species spread over $\sim 80 \%$ of cover at all three sites. The CHV values of the sets of 50 spectra of each common abundant species from each of the $0.05^{\circ}$ CHIRPS grid cells across rainfall gradient showed that rainfall has a positive effect on intra-species $\mathrm{CHV}$ values, indicating a dynamic range in their functional diversity. $\mathrm{CHV}$ s increased over rainfall gradient consistently across the sites ( $\left.\mathrm{R}^{2} 0.86-0.98\right)$. Across species, $\mathrm{CHV}$ variability was relatively narrow for $T$. grandis (Figure 9) and substantially higher for F. racemosa and bamboo species. Inter-species variability was found to be relatively higher at MTR (Figure S4).

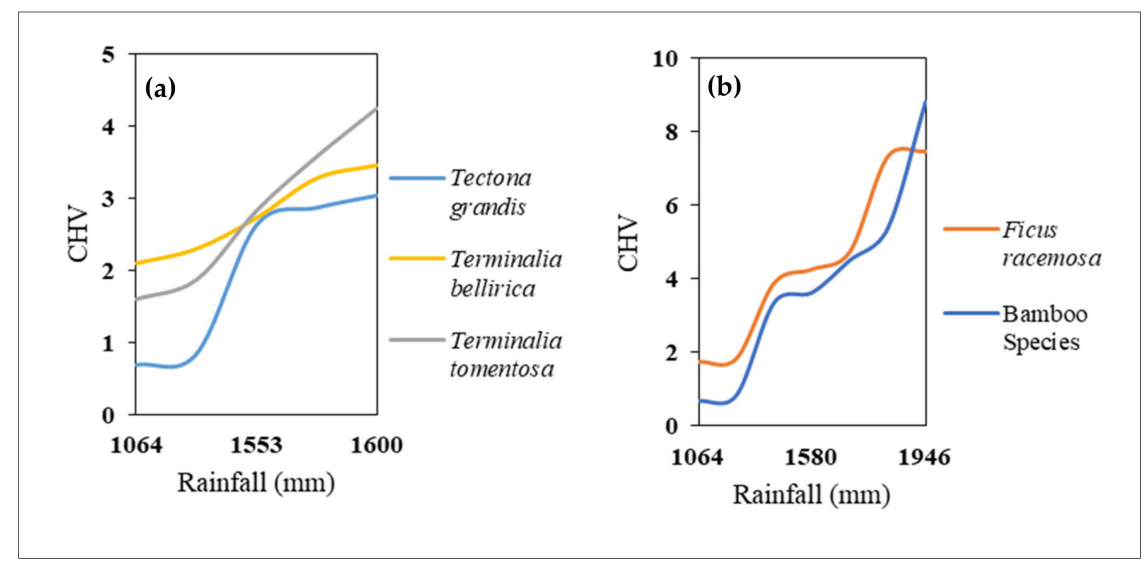

Figure 9. Common abundant species intra-species spectral variability (as seen in CHVs) across the climatic gradient of the three sites. $(n=5$ in $\mathbf{a}, n=7$ in $\mathbf{b})$. 


\subsection{Redundancy Analysis}

Redundancy analysis was performed using climatic data as explanatory variables and species abundance and $\mathrm{CHV}$ values as response variables. RDA plots revealed that species are broadly spread across the climatic gradient. The climatic gradient explained $12-17 \%$ of the variance in the species and spectral diversity distribution of all recorded species at the three sites (Figure S5). The Spectral diversity metrics were observed to be more sensitive compared to the species abundance metrics by showing higher explained variance towards the climatic gradient. The field and spectral diversity metrics of the abundant species as response variables showed higher explained variance, as shown in Figure 10, indicating that $13-24 \%$ of the variance in the distribution of the species by site matrix was because of the climatic gradient.

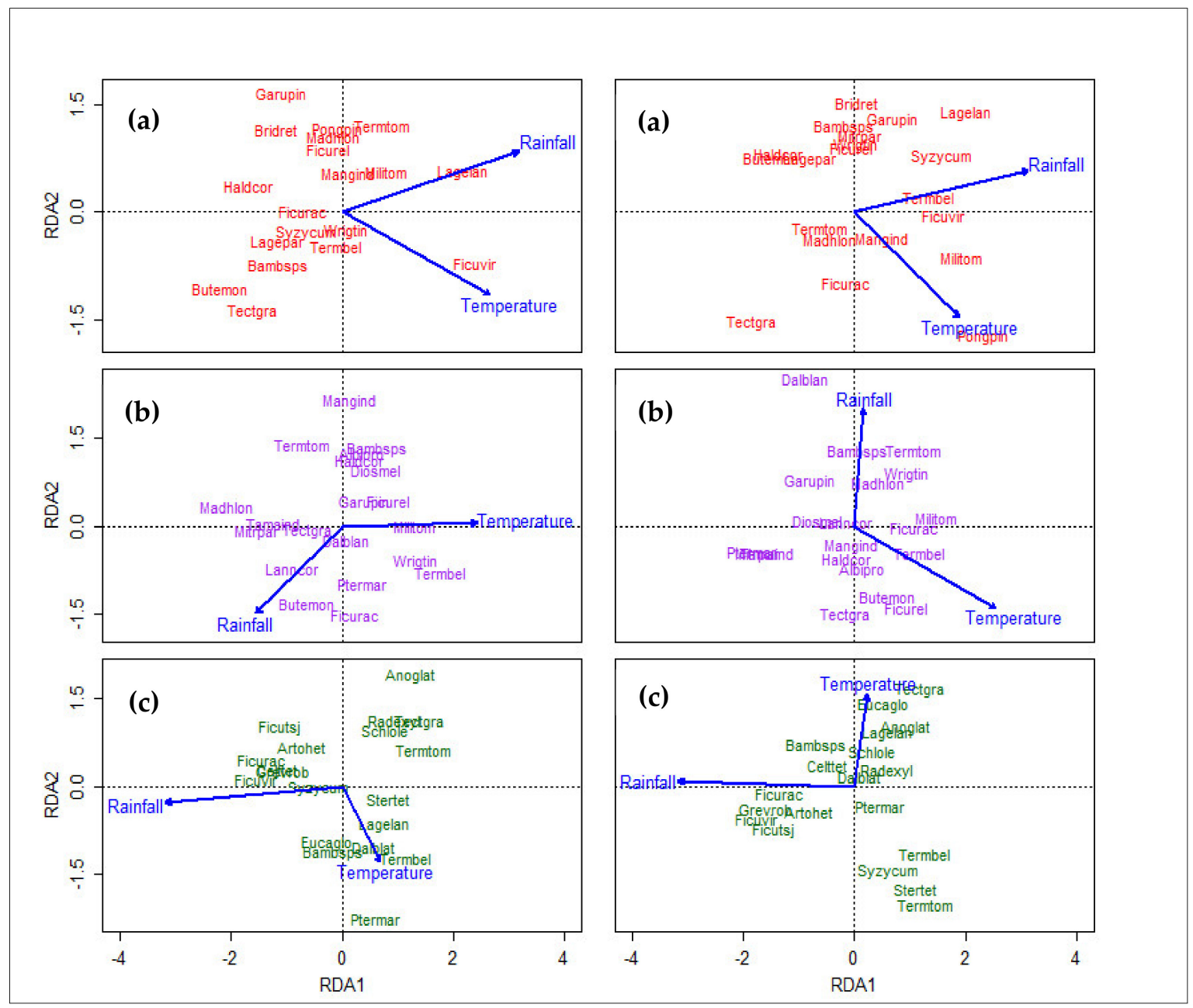

Figure 10. Redundancy analysis output of abundant species distribution values (left) and spectral diversity as CHVs (right) (considered as response variables) with climatic gradient (explanatory variable). The variance explained for species distribution ranged between 13-24\%, and for spectral diversity as CHVs, varied between 14-23\%. (a) SWS, (b) VNP, and (c) MTR.

\subsection{Caveats}

The level of uncertainty in spectral diversity measurements can be impacted by the classification accuracy of species maps and the available number of spectra for lesser distributed species. Our results indicate that the selected field plots numbers were reasonable for these sites. Other regions with variable species and spectral diversity metrics may require different sampling scales for correlating with the measured inputs. 


\section{Discussion}

\subsection{Tree Species Diversity Metrics}

The present study focuses on measuring the tree diversity of three sites of a megadiverse tropical country, India, using field-based and remote sensing techniques, which is of importance to forest managers and conservationists [45]. Measured dissimilarity indices indicated that spectral diversity metrics can provide a better understanding of the diversity compared to sampling-based field study metrics. Amongst the tree species recorded (70-80 species), field-based metrics revealed that around a quarter of them are seen as abundant, and this pattern is referred to as an established attribute of communities [46]. Similar to previous findings [47,48], of the 31 common species of the three sites, 11 were found to co-occur as abundant species at MTR, 14 at VNP, and 15 at SWS, showing site- and climatic gradient-specific distributions, resulting in disparate inter-specific interactions. The differences in species composition, seen here across climatic gradient, are congruent to the studies reported earlier across rainfall gradients and drought $[49,50]$. A few of the species, such as Gmelina arborea, showed sparse distribution at all the three sites, indicating that some of the species inherently show restricted spread, irrespective of the observed climatic variability. These observed shifts in community composition can eventually determine the growth rates and productivity [3] of the three sites, which have a long-term impact on prevailing forest structure and function. The trends in spectral CHVs observed across the three sites of this study indicate that species assemblages may have strong local controls, and the corresponding patterns of co-occurrence are largely aligned along major climatic gradient. As observed earlier in [51], ecological and remote sensing products together, as reported in this study, can improve the verity of ecological models for effective forest management.

The congruence observed in the field- and spectra-based diversity metrics and the increase in the measured CHVs proportionate to abundant species per unit area (Figure 4) affirm the utility of spectral diversity metrics in measuring biodiversity. A similar association was reported between species richness and spectral diversity [52]. The higher rainfall observed at MTR resulted in a larger number of recorded tree species (by 15\%), and significantly higher spectral diversity, as observed in the CHVs of abundant species (nearly twice that of the readings at SWS) compared to the other two sites. Spectral diversity positively increased across the climatic gradient, affirming the positive impact of rainfall on diversity. The flattening of the species-area curves appeared first for abundant species and later for all the recorded species. This pattern was reversed for spectral diversity-area curves, indicating that greater intra-species variability, as seen in the abundant species of this study, may have a surprise impact on biodiversity estimates coming from remote sensing [16], and this is to be factored in while projecting biodiversity estimates of the tropics using remote sensing. Higher intra-species variability amongst the abundant species of the three sites, as seen from CHVs, could be one of the many reasons for their expansive reach at the three sites. As mentioned by Avolio et al. [46], our study makes an effort in estimating abundant species distribution over larger spatial scales through remote sensing and conveys functional diversity through spectral diversity metrics, which may not be visible in traditional field-based studies.

Random plots of each site, selected from the forest cover maps of the three sites, showed different spectral diversity values (Figure 7) from the ones reported by Dahlin (whose study area was forests sof southwestern Michigan, USA) [22], demonstrating how effectively the spectral data of AVIRIS-NG correlates with tree species diversity observed in the tropical cover of this study. Similar to the observation of Wang and Gamon [10], our work supports and strengthens the efficacy of high resolution remote sensing data in the assessment of biodiversity variables of forest cover through spectral diversity metrics.

\subsection{Abundant Species Maps}

The abundant species maps of the three sites showed a higher accuracy and matching similarity with field-observed data. The corroboration of the developed species maps with additional field visits 
showed a $>85 \%$ match. Classification accuracy is mostly dependent on intra- and inter-species spectral variability $[53,54]$. This is evident in the spectra of abundant species, which resulted in developing classification maps showing $>75 \%$ accuracy in the classification of $\sim 20$ tropical tree species spread over $\sim 80 \%$ of the forest cover of the three sites, revealing the advantage of AVIRIS-NG in tree enumeration studies over expansive regions. As reported earlier, the distribution and spread of abundant species canopies [55] and the quality of extracted endmember spectra [10] made it possible to have abundant species maps of the three sites with better accuracy. Earlier, Ferreira et al. [54] reported 81-84\% user's accuracy for eight tree species of tropical deciduous forests using hyperspectral data with a 1-m spatial resolution. With seven individual tree species and an additional class of broadleaved ones in forest cover in Poland, Modzelewska et al. [56] reported 77\% accuracy in classification using 5-m resolution hyperspectral data. The user's accuracy values of this study (83.54-86.70\%) for 20 tropical tree species with 4-m spatial resolution data are reasonable. The distribution maps of abundant species developed here by using high resolution sensors provide valuable inputs for forest ecological studies [57] and also for forest management.

\subsection{Intra- and Inter-Species Spectral Variability}

Jetz et al. [58] indicated that spectra reveal biochemical and structural aspects of vegetation, assisting in tracking plant functional diversity remotely. Schweiger et al. [14] underlined the importance of plant spectral diversity in predicting the ecosystem functionality of Cedar Creek. These reports broadly support the foundation of this study. Though transformations, such as PCA, do not directly represent measured traits, the $\mathrm{CHV}$ metric calculated here indirectly expresses the multivariate range of trait values captured through the variability of spectra collected via the high-fidelity AVIRIS-NG instrument, as in [44]. Patterns of intra- and inter-species variability in CHVs across the three sites (Table S10) help show the variability in canopy traits and simultaneously help elucidate the variations in traits along a major climatic gradient. The $\mathrm{CHVs}$ of species with restricted distributions are relatively lower when compared to the abundant species, indicating a high degree of trait conservatism.

Albert et al. [59] emphasized considering intra-specific variability in plant ecology, and Siefert et al. [60] reported that $25 \%$ of trait variation in a community is because of intra-species variability. The observed intra-species variability of abundant species in measured CHVs, and on species assemblages over the three sites, is in sync with these reports. Functional variability can be looked at from an individual perspective or at the species-based [61] and community level. These are evident from the consistent increase in the $\mathrm{CHVs}$ of the common abundant species across the climatic gradient over the three sites (Figure 9). Poorter et al. [61] reported 44\% trait variation within the most abundant species. The amplitudes of intra-specific variability among abundant species, seen in this study, are large. Additionally, the dynamics in CHV values are species-specific. Bolnick et al. [62] suggested how intra-specific trait variation can modulate species abundance and interaction, impacting community dynamics. Similar reasoning can be given for the observed dynamics of abundant species distribution over the three sites of this study.

\subsection{Climatic Gradient and Species Response}

RDA, performed primarily as a constrained ordination technique, showed the impact of the climatic gradient on the spread of tree species. The impact of the climatic gradient is evident in the direction and spread of the arrows in the RDA plot (Figure 10), indicating a constrained response of species spread towards environmental variables with high positive, negative, and near zero correlations. Climatic gradient explained more variance about the abundant species distribution, revealing their explicit response, with $\sim 80 \%$ occupancy at each site. The explained variance increased from SWS to VNP to MTR, showing positivity in the distribution dynamics of recorded tropical tree species over the climatic gradient. The measured variance values went down for the RDA of all recorded species, indicating that sensitivity towards climatic gradient could be different for abundant species compared to others. Though the percentage of variation in species distribution, explained by the observed 
gradient, appears smaller at the lower end, values at the upper end can match with the ones given for the three different factors of woody plants of the Panama Republic [63]. Though further confirmations are needed, it is interesting to notice how the same common species place themselves in site-specific community conformations in response to rainfall variability. Stavros et al. [64] raised the question, "do diverse communities respond to climate change differently from simpler communities?". The outputs of the multivariate analysis of this study are indicative of a similar approach by the recorded species of this study.

\section{Conclusions}

This study utilized a large field-sampled dataset over a climatic gradient to leverage imaging spectroscopy data from the joint ISRO-NASA AVIRIS-NG India campaign to help generate an understanding of the patterns of linkage between tree species field and spectral diversity metrics. High resolution datasets worked effectively in developing abundant species maps, finding out intraand inter-species variability as CHVs within and over three sites in the tropics. Similar to the report of [65], which mentioned that climate primarily drives the distribution of regional species, the climatic gradient in this study was shown to impact the spread and dispersion of abundant tree species of three sites differently, leading to site-specific strategic species assemblages. The response of two of the important species, $T$. grandis and bamboo species, depict how well these species can tune their inherent functional diversity towards climatic gradient. The findings of this study are relevant in providing vital inputs to the management of these precious and vulnerable forest covers, and support the view in [66] that an integrative approach of remote sensing and vital field data has huge potential in the conservation of nature. The outputs of this study, coming from regions less represented in the global database, can contribute to global models. Observed changes in species distribution and diversity metrics over climatic gradient can help in assessing these forests' responses to the projected dynamics in rainfall over the coming decades.

Supplementary Materials: The following are available online at http://www.mdpi.com/2072-4292/12/13/2130/s1.

Author Contributions: N.S.R.K. conceived the idea and designed the experiments. A.N.C., M.G.D., and R.M.P. equally and collectively carried out field work, AVIRIS-NG data processing, and statistical analysis. P.M. assisted in remote sensing data processing. N.S.R.K. wrote the first draft of the manuscript. P.M. and A.S. made extensive edits to the first draft. All authors contributed to the final version. B.B. is the coordinator of the AVIRIS-NG India program. All authors have read and agreed to the published version of the manuscript.

Funding: This research was funded by the DST-NISA program (BDID/01/23/2014-HSRS/20) and the SAC-ISRO-AVIRIS-NG-AO program.

Acknowledgments: The authors are thankful to Mr. Rajesh Kallaje, IFS and Mrs. Aradhana Sahu, IFS for field work support. We are very much thankful to Philip Townsend, Adam Chlus, and Zhiwei Ye at the University of Wisconsin for sharing topographic and BRDF-corrected AVIRIS-NG images for the three sites. The authors are thankful to the reviewers for their critical suggestions.

Conflicts of Interest: The authors declare no conflict of interest.

\section{References}

1. Esquivel-Muelbert, A.; Baker, T.R.; Dexter, K.G.; Lewis, S.L.; ter Steege, H.; Lopez-Gonzalez, G.; Mendoza, A.M.; Brienen, R.; Feldpausch, T.R.; Pitman, N.; et al. Seasonal drought limits tree species across the Neotropics. Ecography 2017, 40, 618-629. [CrossRef]

2. Kraft, N.J.B.; Valencia, R.; Ackerly, D.D. Functional Traits and Niche-Based Tree Community Assembly in an Amazonian Forest. Science 2008, 322, 580-582. [CrossRef] [PubMed]

3. Zhang, T.; Niinemets, Ü.; Sheffield, J.; Lichstein, J.W. Shifts in tree functional composition amplify the response of forest biomass to climate. Nature 2018, 556, 99-102. [CrossRef]

4. Knapp, A.K.; Ciais, P.; Smith, M.D. Reconciling inconsistencies in precipitation-productivity relationships: implications for climate change. New Phytol. 2017, 214, 41-47. [CrossRef] 
5. Babst, F.; Poulter, B.; Trouet, V.; Tan, K.; Neuwirth, B.; Wilson, R.; Carrer, M.; Grabner, M.; Tegel, W.; Levanic, T.; et al. Site- and species-specific responses of forest growth to climate across the European continent. Glob. Ecol. Biogeogr. 2013, 22, 706-717. [CrossRef]

6. Kapos, V. Seeing the forest through the trees. Science 2017, 355, 347-349. [CrossRef]

7. Poorter, L.; Wright, S.J.; Paz, H.; Ackerly, D.D.; Condit, R.; Ibarra-Manríquez, G.; Harms, K.E.; Licona, J.C.; Martínez-Ramos, M.; Mazer, S.J.; et al. Are Functional Traits Good Predictors of Demographic Rates? Evidence from Five Neotropical Forests. Ecology 2008, 89, 1908-1920. [CrossRef]

8. Pélissier, R. Tree spatial patterns in three contrasting plots of a southern Indian tropical moist evergreen forest. J. Trop. Ecol. 1998, 14, 1-16. [CrossRef]

9. Swenson, N.G. The assembly of tropical tree communities-The advances and shortcomings of phylogenetic and functional trait analyses. Ecography 2013, 36, 264-276. [CrossRef]

10. Wang, R.; Gamon, J.A. Remote sensing of terrestrial plant biodiversity. Remote Sens. Environ. 2019, 231, 111218. [CrossRef]

11. Díaz, S.; Kattge, J.; Cornelissen, J.H.C.; Wright, I.J.; Lavorel, S.; Dray, S.; Reu, B.; Kleyer, M.; Wirth, C.; Colin Prentice, I.; et al. The global spectrum of plant form and function. Nature 2016, 529, 167-171. [CrossRef]

12. Schepaschenko, D.; See, L.; Lesiv, M.; Bastin, J.-F.; Mollicone, D.; Tsendbazar, N.-E.; Bastin, L.; McCallum, I.; Laso Bayas, J.C.; Baklanov, A.; et al. Recent Advances in Forest Observation with Visual Interpretation of Very High-Resolution Imagery. Surv. Geophys. 2019, 40, 839-862. [CrossRef]

13. Hill, J.; Buddenbaum, H.; Townsend, P.A. Imaging Spectroscopy of Forest Ecosystems: Perspectives for the Use of Space-borne Hyperspectral Earth Observation Systems. Surv. Geophys. 2019, 40, 553-588. [CrossRef]

14. Schweiger, A.K.; Cavender-Bares, J.; Townsend, P.A.; Hobbie, S.E.; Madritch, M.D.; Wang, R.; Tilman, D.; Gamon, J.A. Plant spectral diversity integrates functional and phylogenetic components of biodiversity and predicts ecosystem function. Nat. Ecol. Evol. 2018, 2, 976-982. [CrossRef] [PubMed]

15. Miraglio, T.; Adeline, K.; Huesca, M.; Ustin, S.; Briottet, X. Monitoring LAI, Chlorophylls, and Carotenoids Content of a Woodland Savanna Using Hyperspectral Imagery and 3D Radiative Transfer Modeling. Remote Sens. 2020, 12, 28. [CrossRef]

16. Wang, Z.; Townsend, P.A.; Schweiger, A.K.; Couture, J.J.; Singh, A.; Hobbie, S.E.; Cavender-Bares, J. Mapping foliar functional traits and their uncertainties across three years in a grassland experiment. Remote Sens. Environ. 2019, 221, 405-416. [CrossRef]

17. Kunstler, G.; Falster, D.; Coomes, D.A.; Hui, F.; Kooyman, R.M.; Laughlin, D.C.; Poorter, L.; Vanderwel, M.; Vieilledent, G.; Wright, S.J.; et al. Plant functional traits have globally consistent effects on competition. Nature 2016, 529, 204-207. [CrossRef]

18. Palmer, M.W.; Wohlgemuth, T.; Earls, P.; Arévalo, J.R.; Thompson, S.D. Opportunities for long-term ecological research at the Tallgrass Prairie Preserve, Oklahoma. In Proceedings of the ILTER Regional Workshop: Cooperation in Long Term Ecological Research in Central and Eastern Europe, Budapest, Hungary, 22-25 June 1999; Volume 2229, p. 123128.

19. Palmer, M.W.; Earls, P.G.; Hoagland, B.W.; White, P.S.; Wohlgemuth, T. Quantitative tools for perfecting species lists. Environmetrics 2002, 13, 121-137. [CrossRef]

20. Rocchini, D.; Chiarucci, A.; Loiselle, S.A. Testing the spectral variation hypothesis by using satellite multispectral images. Acta Oecologica 2004, 26, 117-120. [CrossRef]

21. Asner, G.P.; Martin, R.E. Spectranomics: Emerging science and conservation opportunities at the interface of biodiversity and remote sensing. Glob. Ecol. Conserv. 2016, 8, 212-219. [CrossRef]

22. Dahlin, K.M. Spectral diversity area relationships for assessing biodiversity in a wildland-agriculture matrix. Ecol. Appl. 2016, 26, 2758-2768. [CrossRef]

23. Gholizadeh, H.; Gamon, J.A.; Zygielbaum, A.I.; Wang, R.; Schweiger, A.K.; Cavender-Bares, J. Remote sensing of biodiversity: Soil correction and data dimension reduction methods improve assessment of $\alpha$-diversity (species richness) in prairie ecosystems. Remote Sens. Environ. 2018, 206, 240-253. [CrossRef]

24. Bello, F.D.; Lepš, J.; Sebastià, M.-T. Predictive value of plant traits to grazing along a climatic gradient in the Mediterranean. J. Appl. Ecol. 2005, 42, 824-833. [CrossRef]

25. Díaz, S.; Cabido, M.; Zak, M.; Carretero, E.M.; Araníbar, J. Plant functional traits, ecosystem structure and land-use history along a climatic gradient in central-western Argentina. J. Veg. Sci. 1999, 10, 651-660. [CrossRef] 
26. Aguirre-Gutiérrez, J.; Oliveras, I.; Rifai, S.; Fauset, S.; Adu-Bredu, S.; Affum-Baffoe, K.; Baker, T.R.; Feldpausch, T.R.; Gvozdevaite, A.; Hubau, W.; et al. Drier tropical forests are susceptible to functional changes in response to a long-term drought. Ecol. Lett. 2019, 22, 855-865. [CrossRef]

27. Féret, J.-B.; Asner, G.P. Mapping tropical forest canopy diversity using high-fidelity imaging spectroscopy. Ecol. Appl. 2014, 24, 1289-1296. [CrossRef]

28. Martin, M.E.; Plourde, L.C.; Ollinger, S.V.; Smith, M.-L.; McNeil, B.E. A generalizable method for remote sensing of canopy nitrogen across a wide range of forest ecosystems. Remote Sens. Environ. 2008, 112, 3511-3519. [CrossRef]

29. Wieczynski, D.J.; Boyle, B.; Buzzard, V.; Duran, S.M.; Henderson, A.N.; Hulshof, C.M.; Kerkhoff, A.J.; McCarthy, M.C.; Michaletz, S.T.; Swenson, N.G.; et al. Climate shapes and shifts functional biodiversity in forests worldwide. Proc. Natl. Acad. Sci. USA 2019, 116, 587-592. [CrossRef]

30. Lewis, S.L. Tropical forests and the changing earth system. Philos. Trans. R. Soc. B: Biol. Sci. 2006, 361, 195-210. [CrossRef]

31. Enquist, B.J.; Enquist, C.A.F. Long-term change within a Neotropical forest: assessing differential functional and floristic responses to disturbance and drought. Glob. Chang. Biol. 2011, 17, 1408-1424. [CrossRef]

32. Lewis, S.L.; Sonké, B.; Sunderland, T.; Begne, S.K.; Lopez-Gonzalez, G.; van der Heijden, G.M.F.; Phillips, O.L.; Affum-Baffoe, K.; Baker, T.R.; Banin, L.; et al. Above-ground biomass and structure of 260 African tropical forests. Philos. Trans. R. Soc. B Biol. Sci. 2013, 368, 20120295. [CrossRef] [PubMed]

33. Roy, A.; Roy, P.S. Biodiversity information in India: Status and future scope. In Biodiversity in Tropical Ecosystems; Springer: Berlin, Germany, 2015; pp. 9-13. ISBN 1-55528-370-5.

34. UNNI, N.V.M.; ROY, P.S.; PARTHASARATHY, V. Evaluation of LANDSAT and airborne multispectral data and aerial photographs for mapping forest features and phenomena in a part of the Godavari basin. Int. J. Remote Sens. 1985, 6, 419-431. [CrossRef]

35. Ambastha, K.R.; Jha, C.S. Geospatial analysis of Tamil Nadu Eastern Ghats forest types at landscape level with reference to fragmentation and species diversity. J. Indian Soc. Remote Sens. 2010, 38, 453-463. [CrossRef]

36. Gairola, S.; Procheş, Ş.; Rocchini, D. High-resolution satellite remote sensing: a new frontier for biodiversity exploration in Indian Himalayan forests. Int. J. Remote Sens. 2013, 34, 2006-2022. [CrossRef]

37. Jha, C.S.; Fararoda, R.; Singhal, J.; Reddy, C.S.; Rajashekar, G.; Maity, S.; Patnaik, C.; Das, A.K.; Misra, A.; Singh, C.P.; et al. Characterization of Species Diversity and Forest Health using AVIRIS-NG Hyperspectral Remote Sensing Data. Curr. Sci. 2019, 116, 1124. [CrossRef]

38. Thompson, D.R.; Gao, B.-C.; Green, R.O.; Roberts, D.A.; Dennison, P.E.; Lundeen, S.R. Atmospheric correction for global mapping spectroscopy: ATREM advances for the HyspIRI preparatory campaign. Remote Sens. Environ. 2015, 167, 64-77. [CrossRef]

39. Soenen, S.A.; Peddle, D.R.; Coburn, C.A. SCS+C: a modified Sun-canopy-sensor topographic correction in forested terrain. IEEE Trans. Geosci. Remote Sens. 2005, 43, 2148-2159. [CrossRef]

40. Wanner, W.; Li, X.; Strahler, A.H. On the derivation of kernels for kernel-driven models of bidirectional reflectance. J. Geophys. Res. Atmos. 1995, 100, 21077-21089. [CrossRef]

41. Kindt, R.; Coe, R. Tree Diversity Analysis. A Manual and Software for Common Statistical Methods for Ecological and Biodiversity Studies; World Agro-forestry Center (ICRAF): Nairobi, Kenya, 2006.

42. Green, A.A.; Berman, M.; Switzer, P.; Craig, M.D. A transformation for ordering multispectral data in terms of image quality with implications for noise removal. IEEE Trans. Geosci. Remote Sens. 1988, 26, 65-74. [CrossRef]

43. Cortes, C.; Vapnik, V. Support-vector networks. Mach. Learn. 1995, 20, 273-297. [CrossRef]

44. Cornwell, W.K.; Schwilk, D.W.; Ackerly, D.D. A Trait-Based Test for Habitat Filtering: Convex Hull Volume. Ecology 2006, 87, 1465-1471. [CrossRef]

45. Fassnacht, F.E.; Latifi, H.; Stereńczak, K.; Modzelewska, A.; Lefsky, M.; Waser, L.T.; Straub, C.; Ghosh, A. Review of studies on tree species classification from remotely sensed data. Remote Sens. Environ. 2016, 186, 64-87. [CrossRef]

46. Avolio, M.L.; Forrestel, E.J.; Chang, C.C.; Pierre, K.J.L.; Burghardt, K.T.; Smith, M.D. Demystifying dominant species. New Phytol. 2019, 223, 1106-1126. [CrossRef]

47. Ricklefs, R.E.; Miller, G.L. Ecology, 4th ed.; W.H. Freeman \& Co: New York, NY, USA, 2000; ISBN 978-0-7167-2829-0.

48. Ricklefs, R.E. Disintegration of the Ecological Community. Am. Nat. 2008, 172, 741-750. [CrossRef] 
49. Scheiter, S.; Langan, L.; Higgins, S.I. Next-generation dynamic global vegetation models: learning from community ecology. New Phytol. 2013, 198, 957-969. [CrossRef]

50. Engelbrecht, B.M.J.; Comita, L.S.; Condit, R.; Kursar, T.A.; Tyree, M.T.; Turner, B.L.; Hubbell, S.P. Drought sensitivity shapes species distribution patterns in tropical forests. Nature 2007, 447, 80-82. [CrossRef]

51. Randin, C.F.; Ashcroft, M.B.; Bolliger, J.; Cavender-Bares, J.; Coops, N.C.; Dullinger, S.; Dirnböck, T.; Eckert, S.; Ellis, E.; Fernández, N.; et al. Monitoring biodiversity in the Anthropocene using remote sensing in species distribution models. Remote Sens. Environ. 2020, 239, 111626. [CrossRef]

52. Rocchini, D.; Hortal, J.; Lengyel, S.; Lobo, J.M.; Jiménez-Valverde, A.; Ricotta, C.; Bacaro, G.; Chiarucci, A. Accounting for uncertainty when mapping species distributions: The need for maps of ignorance. Prog. Phys. Geogr. Earth Environ. 2011, 35, 211-226. [CrossRef]

53. Zhang, J.; Rivard, B.; Sánchez-Azofeifa, A.; Castro-Esau, K. Intra- and inter-class spectral variability of tropical tree species at La Selva, Costa Rica: Implications for species identification using HYDICE imagery. Remote Sens. Environ. 2006, 105, 129-141. [CrossRef]

54. Ferreira, M.P.; Zortea, M.; Zanotta, D.C.; Shimabukuro, Y.E.; de Souza Filho, C.R. Mapping tree species in tropical seasonal semi-deciduous forests with hyperspectral and multispectral data. Remote Sens. Environ. 2016, 179, 66-78. [CrossRef]

55. Ustin, S.L.; Gamon, J.A. Remote sensing of plant functional types. New Phytol. 2010, 186, 795-816. [CrossRef]

56. Modzelewska, A.; Fassnacht, F.E.; Stereńczak, K. Tree species identification within an extensive forest area with diverse management regimes using airborne hyperspectral data. Int. J. Appl. Earth Obs. Geoinf. 2020, 84, 101960. [CrossRef]

57. Vaglio Laurin, G.; Puletti, N.; Hawthorne, W.; Liesenberg, V.; Corona, P.; Papale, D.; Chen, Q.; Valentini, R. Discrimination of tropical forest types, dominant species, and mapping of functional guilds by hyperspectral and simulated multispectral Sentinel-2 data. Remote Sens. Environ. 2016, 176, 163-176. [CrossRef]

58. Jetz, W.; Cavender-Bares, J.; Pavlick, R.; Schimel, D.; Davis, F.W.; Asner, G.P.; Guralnick, R.; Kattge, J.; Latimer, A.M.; Moorcroft, P.; et al. Monitoring plant functional diversity from space. Nat. Plants 2016, 2, 1-5. [CrossRef]

59. Albert, C.H.; Grassein, F.; Schurr, F.M.; Vieilledent, G.; Violle, C. When and how should intraspecific variability be considered in trait-based plant ecology? Perspect. Plant Ecol. Evol. Syst. 2011, 13, 217-225. [CrossRef]

60. Siefert, A.; Violle, C.; Chalmandrier, L.; Albert, C.H.; Taudiere, A.; Fajardo, A.; Aarssen, L.W.; Baraloto, C.; Carlucci, M.B.; Cianciaruso, M.V.; et al. A global meta-analysis of the relative extent of intraspecific trait variation in plant communities. Ecol. Lett. 2015, 18, 1406-1419. [CrossRef] [PubMed]

61. Poorter, L.; Castilho, C.V.; Schietti, J.; Oliveira, R.S.; Costa, F.R.C. Can traits predict individual growth performance? A test in a hyperdiverse tropical forest. New Phytol. 2018, 219, 109-121. [CrossRef]

62. Bolnick, D.I.; Amarasekare, P.; Araújo, M.S.; Bürger, R.; Levine, J.M.; Novak, M.; Rudolf, V.H.W.; Schreiber, S.J.; Urban, M.C.; Vasseur, D.A. Why intraspecific trait variation matters in community ecology. Trends Ecol. Evol. 2011, 26, 183-192. [CrossRef]

63. Svenning, J.-C.; Kinner, D.A.; Stallard, R.F.; Engelbrecht, B.M.J.; Wright, S.J. Ecological Determinism in Plant Community Structure Across a Tropical Forest Landscape. Ecology 2004, 85, 2526-2538. [CrossRef]

64. Stavros, E.N.; Schimel, D.; Pavlick, R.; Serbin, S.; Swann, A.; Duncanson, L.; Fisher, J.B.; Fassnacht, F.; Ustin, S.; Dubayah, R.; et al. ISS observations offer insights into plant function. Nat. Ecol. Evol. 2017, 1, 0194. [CrossRef]

65. van Ewijk, K.Y.; Randin, C.F.; Treitz, P.M.; Scott, N.A. Predicting fine-scale tree species abundance patterns using biotic variables derived from LiDAR and high spatial resolution imagery. Remote Sens. Environ. 2014, 150, 120-131. [CrossRef]

66. Hoffmann, S.; Schmitt, T.M.; Chiarucci, A.; Irl, S.D.H.; Rocchini, D.; Vetaas, O.R.; Tanase, M.A.; Mermoz, S.; Bouvet, A.; Beierkuhnlein, C. Remote sensing of $\beta$-diversity: Evidence from plant communities in a semi-natural system. Appl. Veg. Sci. 2019, 22, 13-26. [CrossRef]

(C) 2020 by the authors. Licensee MDPI, Basel, Switzerland. This article is an open access article distributed under the terms and conditions of the Creative Commons Attribution (CC BY) license (http://creativecommons.org/licenses/by/4.0/). 